\title{
THE IMPACT OF COHORT MEMBERSHIP ON DISPOSABLE INCOMES IN WEST GERMANY, FRANCE AND THE US
}

Do some birth cohorts monopolize lucrative positions and social transfers, so that they are unduly advantaged over others? In a world without such intercohort-inequalities, a cohort born into an economy that is, say, two percent richer, should have two percent more disposable income over its life-course. In reality however, increasing prosperity could have bypassed some birth cohorts, while others disproportionately reaped the fruits of economic growth, appropriating lucrative positions and social transfers, thereby disadvantaging other birth cohorts. We measure whether this happened for birth cohorts of the $20^{\text {th }}$ century in West Germany, France and the US. We show how much belonging to a certain birth cohort influences incomes in these three countries and whether they advantage some birth cohorts while disadvantaging others. The existing literature has speculated on this question, but not answered it. This is largely due to methodological limitations, as we show below.

We use an age-period-cohort (APC) analysis. This research tradition started with Mannheim (1928), who proposed to conceptualize social change as the result of new birth cohorts replacing old ones. Each birth cohorts shares a socialization, as it grows up in a similar historical period, which can durably mark or even collectively "scar" a generation (Mannheim 1928: 311f.). Notably, some cohorts may have had an easy entry into the labor market during an economic boom. But a later generation may have to establish itself during the slump that follows the boom, from which a preceding generation profited. For example, cohorts that became adults during the Great Depression are less likely to invest in the stock market; they are scarred in the sense of being more risk-averse (Malmendier / Nagel 2011). Other cohorts grew up when entry into the working market was difficult, which may have disadvantaged them economically. This led scholars to hypothesize about systematic cycles of "lucky and less lucky generations" (Myles 2002: 138).

We argue here that the differential fate of cohorts may differ from country to country. Notably, while a succession of more or less favored birth cohorts may be unavoidable, conservative welfare states, such as France and Germany, are known to use employment protection and seniority rights to protect those that hold a stable job ("insiders") against those who do not hold a stable job ("outsiders"), to preserve social stability (Ferrera 1996; 2010; Lessenich 1994; Buchholz, et al. 2009). The post-1970s liberalization of conservative welfare states exacerbated this trend, arguably in France even more so than in Germany (Palier 2010: 96f.; also cf. Karamessini 2008: 66; Ferrera 2010: 625; Buchholz, et al. 2009). One could therefore suppose that German and French cohorts entering the labor market after 1970 are disadvantaged, as they entered a rigid labor market during a time when economic growth ceased to make up new room for outsiders, while labor regulations kept on protecting insiders. To test whether this is indeed the case, we contrast these two conservative welfare states with the US, the quintessential liberal welfare state. While inequalities have increased in the US, liberalization US-style did not protect a group of insiders against outsiders, but exposed everyone to the market, contrary to what conservative welfare states do (Thelen 2012; Schröder 2013). Thus, in the US, one would not expect that birth cohorts that entered the labor market in the 1970s and later are disadvantaged. The welfare state literature furnishes these hypotheses. However, as of yet, the literature is unable to answer them, as the following literature review will show. 
An analysis by Blossfeld (1986: 219) gives reason to argue that baby-boomers are advantaged, as he shows that West German cohorts born around 1951 entered higher-prestige jobs than cohorts born around 1929. Lauterbach and Sacher (2001) in turn documented that German men born between 1955 and 1970 are more often unemployed and in insecure employment relative to men born between 1935-1940; but they document a contrary trend for women. For men, this illustrates our general hypotheses: cohorts that entered the labor market during favorable times have incomes above long-run trends, while cohorts entering the labor market in unfavorable times are durably disadvantaged, they do not make up for a problematic entry into the labor market. Boockmann and Steine (2006) compared West German cohorts born between 1925 and 1974, showing that monetary returns to education decreased over time. This also indicates that in spite of educational upgrading, it remains problematic to enter the labor market in less favorable times. In a US-German comparison, Antonczyk, DeLeire and Fitzenberger (2010) showed that German late- and early- born male cohorts (born close to 1930 or close to 1980) have lower market wages - relative to overall wage levels - than cohorts born in the midele of the $20^{\text {th }}$ century, between 1940 and 1970 . Their paper finds smaller cohort effects for the US. However, they only look at market wages, though to understand whether certain cohorts are advantaged overall, it makes more sense to look at overall living standards and thus net wages. Studies that are interested in such living standards of different cohorts over long periods of time, however lack the age-period-cohort data necessary to disentangle cohort- from age-effects; they therefore remain speculative (Kohli 2006; Liebig / Scheller 2007). Lacking a methodology to disentangle cohort- from age-effects, scholars complain that "as soon as one tries to describe generations as social collectives, one gets confronted with a set of rather severe difficulties that hinder a clear and concise operationalization" (May 2012: 19).

For the US, Kotlikoff (1992) popularized the argument that older birth cohorts monopolized lucrative positions, so that younger birth cohorts are "born to pay" for them (Longman 1987). However, due to the aforementioned methodological problems, it is so far unclear whether this is actually true or just speculation. Bommier et al. (2010), who only look at transfers and not living standards, argue that all cohorts born after 1930 benefited from public social transfers. Kopczuk, Saez and Song (2010) document decreasing within-cohort inequality until the birth cohort of early 1950 and increasing intra-cohort inequality for later born cohorts (also cf. Antonczyk / DeLeire / Fitzenberger 2010). But while these studies show that inequality within birth cohorts increases over time, they leave the question open how much belonging to a certain birth cohorts influences one's income in the first place (Bönke / Corneo / Lüthen 2012; Fitzenberger, et al. 2001; Osberg 2003).

The literature on France supposes the strongest cohort effects on income. Gollac and Baudelot (1997) described how each new cohort entered the labor market with a higher starting salary until 1975. Chauvel (1997a) showed that cohorts born after 1955 are less socially mobile than pre-1955-cohorts. Post-1955 birth cohorts also participate less politically, are less healthy and have higher suicide rates, possibly partially because of their difficult entry into the labor market (Chauvel 1997b; Anguis / Cases / Surault 2002; Koubi 2003). After scholars even detected systematic downward intergenerational mobility of post-1960 birth cohorts (Peugny, 2009) others explained this by diminishing returns to increasing education (Chauvel 2010a; Chauvel 2010b; Bugeja 2009; Farges 2012). However, while the French literature is not silent about intercohort-inequalities, it still leaves important questions open. Not only do some scholars argue, against the general trend, that French later-born cohorts have caught up again (Bonnet 2010). Also, and mixed with this, it remains unclear whether post-1950-cohorts face a slower 
rise, a stagnation, or indeed an absolute decline of disposable incomes, relative to early-born cohorts. Existing research also does not answer how much education and other copingmechanisms make up for the depressing effect of a difficult labor market entry on living standards.

Thus, the literature argues it is necessary to understand which generations are favored and which not. However, there are no actual calculations of how living standards of $20^{\text {th }}$ century birth cohorts differ. Particularly, we cannot yet "answer the question of which generations get what, when and how" (Goerres / Vanhuysse 2012: 1; also cf. Mayer 2009: 424; 2005: 18). In spite of lacking reliable data to make such sweeping claims, some authors argue that "European societies, in whatever context, do not show signs of generational conflict" (Attias-Donfut / Arber 2000: 18). Using a fairly new methodology, we show that indeed France advantages mid- $20^{\text {th }}$ century birth cohorts to the detriment of early- and late-20 $0^{\text {th }}$ century cohorts. This is much less the case for Germany and not at all for the US. In the following, we introduce the age-periodcohort models that lead to these results.

\section{METHOD}

Age-period-cohort models explain outcomes through the combined effect of three influences: an individual's age a (variable $\alpha_{a}$ ), cohort membership c (variable $\gamma_{c}$ ) and period of measurement $p$ (variable $\pi_{\mathrm{p}}$ ). This leads to the equation:

$\mathrm{y}^{\mathrm{apc}}=\mu+\alpha_{\mathrm{a}}+\pi_{\mathrm{p}}+\gamma_{\mathrm{c}}(\mathrm{APC})$

An APC model can detect how an outcome is explained by position in the life cycle (age effect), time of measurement (period effect) and date of birth (= age at a certain period $=$ cohort effect). While many papers proposed empirical estimations of the three effects (Mason, et al. 1973; Fienberg / Mason 1979), an "identification problem" besets all APC models (Glenn 1976; Mason / Wolfinger 2001). This arises from the equation: a=p-c. That is, each variable is a combination of the other two. To illustrate this problem, consider the following table.

[Table 1 here]

The table shows fictitious average earnings (say, in hourly euros) for people with different ages at different times. Problematically, the same linear trend of income-change can either be understood as a) a combination of an age effect (income increases by 5 euro per 5 -year age group) plus a period effect (income increases by 1 euro per 5-year period) and as an age effect (again, income increases by 5 euro per 5 -year age group) plus a cohort effect (each cohort earns 1 euro more than the preceding one). In more general terms, if a variable linearly depends on age, period and cohort, then an infinite number of decompositions between these effects fit the data and no statistical model can overcome this intrinsic indetermination (Holford 1991; Tu, et al. 2011: 2; Luo 2013).

The first possible solution to deal with this problem is to arbitrarily constrain an APC model. Many researchers hold the first and the last coefficient of the cohort vector equal. When one does this, the number of cases in these extreme cohorts is low, leading to large confidence 
intervals when trying to estimate effects. Yang and Land (2013: 65) call this solution the CGLIM (the "conventional" constrained general linear model). They rightly criticize it as arbitrary.

The second solution to the indetermination-problem is a subgroup of the previous one. Since $\mathrm{a}=\mathrm{p}-\mathrm{c}$ means a collinearity of the three variables, let us suppress one of the linear trends (not the non-liner bumps) of the set (a, p, c), and then suppress for instance period (p), so that the cohort (c) trend will absorb all the long-term linear improvements we should attribute to either period (p) or cohort (c); such a solution is rather common (Mason / Wolfinger 2001), and we can call it APCT (trended). It thus attributes the long-term linear trend that remains after controlling for age to the sole cohorts, not to periods; this shows whether in absolute terms at the same age later-born cohorts do better than previous ones did. The problem is that while this shows whether subsequent cohorts are doing better or worse, e.g. in terms of income, this cohort trend is strictly speaking not weighed against a period trend, but simply absorbs this trend. It has nothing to do with an idea of time-based causality and this choice is highly depending on the window of observation: in empirical cases, it is possible to show that if non-linear bumps between lucky and unlucky cohorts are relatively stable, but trended cohort effects as defined in an APCT are depending on the existence or not of economic growth on that period. Further economic deceleration can substantially impact this cohort trend.

The third solution is the APC-IE (intrinsic estimator) of Yang et al. (2008), which tries to solve the indetermination problem by a Principal Component Analysis of the age, period and cohort vectors. This reduces the linear trend of the three variables to two dimensions. Yang et al. claim that this yields the intrinsic linear influence of each variable, so that the linear age, period and

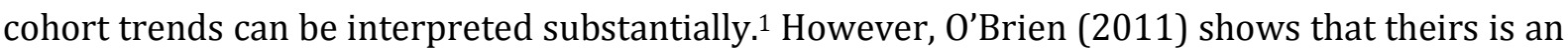
arbitrary choice as well, which fails to deliver substantive linear time trends. It also fails empirical tests. For example, the APC-IE model detects strongly declining educational levels by age (not shown here, code and results uploaded as online annex), which makes no substantive sense, as individuals cannot lose their primary, secondary or tertiary education over time.

The fourth solution is the hierarchical age-period-cohort (HAPC) model. It uses mixed multilevel models that conceptualize age as a continuous polynomial level-1 variable and period and cohort as categorical level-2 variables (Yang / Land 2008; 2013). This model thus assumes that people with a certain age are embedded in a certain cohort at a certain point in time. Cohort coefficients from this model may present a non-zero cohort slope, which is difficult to make sense of, while the non-linearity of the model can be meaningfully interpreted (cf. Pampel / Hunter 2012 and the uploaded online annex).

We therefore propose to use an APC-Detrended (APCD) model. ${ }^{2}$ The APCD acknowledges that linear trends in APC models cannot be robustly attributed to age, period and cohort; so the model focuses on how the effect of age, period and cohort fluctuate around a linear trend, which it absorbs. ${ }^{3}$ Following the usual notation of APC models and OLS expressions ${ }^{4}$, we consider a

\footnotetext{
1 Yang and Land (2013) critique the "conventional wisdom" of Holford (1985) and Rodgers (1982), who argue that only the nonlinear, but not the linear components of APC models are estimable. They want to find interpretable trends of age, period and cohort, a quest that Glenn (1976) always found "futile". 2 The APCD is available as a Stata ado-file.

${ }^{3}$ In biostatistics, this model had been developed by Holford $(1983 ; 1991)$ on a Poisson model of vital statistics. His aim was to detect cohort deviations from linear trends.
} 
dependent variable $\mathrm{y}^{\mathrm{apc}}$, as well as the independent variables age a, period $\mathrm{p}$, and cohort membership c. The equation $\mathrm{c}=\mathrm{p}$-a indexes the vectors of coefficients $\alpha_{a}, \pi_{\mathrm{p}}, \gamma_{\mathrm{c}}$. To provide accurate controls, we consider $\mathrm{j}$ covariates $\mathrm{x}_{\mathrm{j}}$ (which can be continuous or binary). Including constraints, the model has the following expression:

$$
\left\{\begin{array}{l}
y^{a p c}=\alpha_{a}+\pi_{p}+\gamma_{c}+\alpha_{0} \text { rescale }(a)+\gamma_{0} \text { rescale }(c)+\beta_{0}+\sum_{j} \beta_{j} x_{j}+\varepsilon_{i} \\
\left(\begin{array}{l}
\sum_{a} \alpha_{a}=\sum_{p} \pi_{p}=\sum_{c} \gamma_{c}=0 \\
\operatorname{Slope}_{a}\left(\alpha_{a}\right)=\operatorname{Slope}_{p}\left(\pi_{p}\right)=\operatorname{Slope}_{c}\left(\gamma_{c}\right)=0 \\
\min (c)<c<\max (c)
\end{array}\right.
\end{array}\right.
$$

$\beta_{0}$ denotes the constant, $\beta_{\mathrm{j}}$ are the coefficients of control variables, $\alpha_{\mathrm{a}}$ is the vector of the age effect, $\pi_{\mathrm{p}}$ is the period vector and $\gamma_{\mathrm{c}}$ is the cohort vector. These vectors exclusively reflect the non-linear effect of age, period and cohort, as we assign two sets of constraints: each vector sums up to zero and its slope is zero. ${ }^{5}$ The terms $\alpha_{0}$ Rescale(a) and $\gamma_{0}$ Rescale(c) absorb linear trends; Rescale is a transformation that standardizes the coefficients $\alpha_{0}$ and $\gamma_{0}$ : it transforms age from the initial code $a_{\min }$ to $a_{\max }$ to the interval -1 to +1 . Finally, since the first and last cohorts appear just once in the model (the oldest age group of the first period and the youngest of the last), their coefficients are instable; we obtain better estimates by excluding them. With these constraints, the model becomes identifiable; it provides a unique solution. The detrended cohort effect (DCE) coefficients $\gamma_{c}$ are zero when cohort effects are absent. In this case, all cohorts behave according to their age and period characteristics, with no cohort-specific behavior. The APCD then provides no improvement compared to a simple age and period model (AP), which consists of:

$$
\left\{\begin{array}{l}
y^{a p}=\alpha_{a}+\pi_{p}+\alpha_{0} \text { rescale }(a)+\pi_{0} \operatorname{rescale}(p)+\beta_{0}+\sum_{j} \beta_{j} x_{j}+\varepsilon_{i} \\
\left\{\begin{array}{l}
\sum_{a} \alpha_{a}=\sum_{p} \pi_{p}=0 \\
\operatorname{Slope}_{a}\left(\alpha_{a}\right)=\operatorname{Slope}_{p}\left(\pi_{p}\right)=0 \\
\min (c)<c<\max (c)
\end{array}\right.
\end{array}\right.
$$

If at least one $\gamma_{c}$ coefficient is significantly different from zero however, some cohorts are above or below the linear trend. In this case, the AP model is insufficient, as some cohorts received more or less than their expected share after period resources have been distributed according to age structures. Comparing the BIC (cf. Raftery 1986) of the AP and APCD models offers another criterion for or against including cohort effects.

When explaining disposable income, substantive reasons exist to focus on deviations from linear trends. Namely, when disposable income increases by a rate of, say, 5 percent every 5 years, and each cohort born 5 years later increases its incomes by 5 percent, our model detects no cohort

\footnotetext{
${ }^{4}$ Since APCD, like APC-IE, is based on a constrained general linear model, it allows any kind of standard specification, including Ordinary Least Squares, Log, Logit or Poisson models; it also allows control variables that could mediate cohort effects (gender, education, occupation, etc.).

5 The constraint Slope ${ }_{a}\left(\alpha_{a}\right)=0$ means the trend of the age effect is zero and is true only if $\Sigma_{a}\left[\left(2 a-a_{\min }-\right.\right.$ $\left.\left.\mathrm{a}_{\max }\right) \alpha_{\mathrm{a}}\right]=0$. This constraint is easily expressed as a linear equation of coefficients. Holford (1991: 454) gave a similar expression for his zero-slope coefficients.
} 
effect, as the long-run linear trend is absorbed by $\alpha_{0}$ and $\pi_{0}$. And indeed there is no cohort effect in the sense that each cohort profits from the overall linear trend in the same way. A second substantive reason to look at deviations from linear trends, is that expectations about disposable incomes adapt to linear trends. No one is surprised if the living standards of one cohort after another increase with the general trend in living standards; sociologically speaking, this is a nonresult. 6

The APCD thus diagnoses whether a certain cohort receives its relative share of period variations. However, even if later-born cohorts are below the incomes trend, they might still have a higher living standard in absolute terms depending on the overall rate of income growth (and compared to former cohorts at the same age). For example, if incomes grow by 2 percent, and a later cohort has a disposable incomes that grew by only 1.5 percent, then yes, that cohort is below the trend, but still better-off than the preceding one. Contrary to this, when a negative cohort effect is stronger than a positive linear trend, the absolute living standard of a cohort decreases.

The above-mentioned APCT ${ }^{7}$ detects such absolute declines or progressions by using an APCD model without the zero-slope constraint in the cohort coefficients. Concretely, the ACPT suppresses the $\gamma_{0}$ rescale(c)-term, so that it cannot absorb the long-term trend. Therefore, the cohort coefficients instead absorb this long-term linear progression trend, while age effects and period fluctuations are controlled for in the same way as in the APCD. Thus, the parameters $\gamma_{c}$ become a trended cohort effect (TCE), which denotes per-cohort change, controlled for age and possible other controls. Just to reiterate however, this cannot resolve the (generally irresolvable) APC identification problem. Instead, APCT-results show the systematic progression of cohorts, at a given age and controlled for period fluctuations (but not long-run period trends). While the model can control period fluctuations, it cannot control long-run period trends but instead ascribes all linear progression of living standards to the different cohorts. Thus in our case, the APCT model shows how inflation-adjusted living standards change on a cohort-bycohort basis, while it cannot distinguish whether the linear part of this increase is due to cohort effects or period effects. This model is therefore logically more descriptive than the APCD. It is also very dependent on the window of observation. Compared to APCD, APCT has the problem that long-term trends depend on the period under study. For example, adding a year with an economic slowdown can substantially decrease the slope of the cohort trend. However, APCT is the only way of understanding whether younger cohort are better off than former ones at the same age. It thus answers Kant's demand to understand whether later-born generations are better off than earlier ones (see footnote 6), even if it cannot disentangle whether this is due to a long-term period or cohort trend and even though it cannot tell whether any trend will continue into the future. The following formula defines the model:

\footnotetext{
6 The underlying "long-term generational progress" assumption argues that we expect later cohorts to benefit from technical, economic and social progress of the past. Immanuel Kant (1784) was the first to highlight this.

${ }^{7}$ We obtained the APCT from the authors of the APCD ado file.
} 


$$
\left\{\begin{array}{l}
y^{a p c}=\alpha_{a}+\pi_{p}+\gamma_{c}+\alpha_{0} \text { rescale }(a)+\beta_{0}+\sum_{j} \beta_{j} x_{j}+\varepsilon_{i} \\
\left\{\begin{array}{l}
\sum_{a} \alpha_{a}=\sum_{p} \pi_{p}=\sum_{c} \gamma_{c}=0 \\
\operatorname{Slope}_{a}\left(\alpha_{a}\right)=\operatorname{Slope}_{p}\left(\pi_{p}\right)=0 \\
\min (c)<c<\max (c)
\end{array}\right.
\end{array}\right.
$$

\section{DATA}

We use data from the Luxembourg Income Study (LIS). To make use of control variables and to have data available in harmonized form for all three countries, we use wave II (around 1984) to wave VI (around 2004) of the LIS data, excluding citizens from former East Germany, as no data for them is available before 1989. Our dependent variable is logged disposable income after public transfers and payments, adjusted for inflation ${ }^{8}$ and equalized by household size (variable "dpi" of the LIS, divided by the square root of household members). We have however run all analyses by not equalizing income by household members and the substantive results are very similar. ${ }^{9}$ We do not look at market income, as it is less helpful to understand the actual living standards of cohorts after welfare state effects, which we are interested in. Also, the problem with looking at market income is that we cannot look at any age groups that might conceivably have been retired already, so that country comparisons using age groups above 55 become difficult. However, we have run all analysis with disposable market income and the trends we show below are essentially the same. ${ }^{10}$ Using disposable income lets us endogenize changing tax, transfer and social policy environments for different cohorts. In addition, the disposable income variable of the Luxembourg Income Study makes it possible to compare countries over time. It cannot capture in-kind benefits; however, these tend to be low in conservative and liberal welfare states anyway - possibly with the exception of French childcare.

As control variables, we use ISCED-codes for education (reference category is lower secondary or below), thus introducing a dummy each for secondary and tertiary education. We also use dummies for sex (reference is male), partner in household (reference is no partner), number of children (reference is no child, dummy each for one, two and more than two children) and immigrant-status. For the US, we substitute "immigrant" by "African-American" to indicate the effect of belonging to a possibly disadvantaged minority. We have uploaded descriptive statistics for all variables as an online annex. ${ }^{11}$ In the following, we first look at detrended cohort effects. ${ }^{12}$

\section{RESULTS}

\footnotetext{
${ }^{8}$ We rely on measures of inflation from the World Bank and deflate all incomes to 2005-values.

${ }^{9}$ For a comparison of results that are equalized by household members to results that are not, compare for the online annex file with the heading "ONLINE ANNEX - Comparison of equalized and non-equalized household incomes." We cluster standard errors on the level of the individual and can also cluster them on the household level, which does not change our results. For a comparison, see the online annex with the heading "ONLINE ANNEX - Cluster errors at household-level."

${ }^{10}$ See the online annex with the heading „ONLINE ANNEX - Comparison market and dpi income."

11 See the uploaded file with the heading "ONLINE ANNEX - Descriptive statistics of the variables used"

12 Stata code for the LIS calculations is uploaded in the online annex with the first line "*ONLINE ANNEX -

Code APC-D W Ger, Fr, US with and without controls."
} 


\section{DETRENDED COHORT EFFECTS}

The following regression table shows the detrended cohort effects without and with control variables for German, French and US-cohorts.

[Table 2 here]

The effects of belonging to different cohorts in model 1 (West Germany), 3 (France) and 5 (the US) are displayed net of non-linear effects of age and period. The control models (model 2 for Germany, model 4 for France and model 6 for the US) add control variables. Looking at the independent variables from top to bottom shows that, in the no-control models (1, 3 and 5), belonging to the first (1920-)cohort, yields an average disposable income that is 4.9 percent below the long-run income trend in West Germany (the label "Cohort 1920" means having been born between 1915 and 1920). The 1945/1950-cohorts are most advantaged in all countries before controls are introduced. They are 7.4/6 percent above the income trend in West Germany, 8.5/10.1 percent in France and 1.6/2.1 percent in the US. The age variables, which are also controlled for linear trends, have the expected values for all countries: disposable income always peaking around age 45-50. The period effects control that incomes during some times are above or below what one would expect given long-run economic growth. The variables "Cohort Trend" and "Age Trend" control for linear increases and decreases of disposable income for different cohorts and an individual's life cycle; the APCT model will focus on these cohort trends.

The variables that follow in the table control the effect on disposable income of being a female head of household, of having one, two or more than two children, of having a secondary or tertiary education, of living with a partner and of being an immigrant (of having non-white skin color in the US). To illustrate the regression results, the following figure plots the cohort effects for the three countries, before (left sided graphs) and after (right-sided graphs) including control variables.

[Figure 1 here]

In Germany, before including controls, the average disposable income of cohorts born in 1920 and 1975, are respectively 4.9 and 4.6 percent below the income trend, while the disposable incomes of the 1945/1950-cohorts are 7.4/6 percent above it. After including controls, the only result that remains significant however, is that the disposable income of the 1945 and 1950cohorts is 5.8 and 4.6 percent above the income that these cohorts would have if all cohorts had participated equally in increases of disposable income (the linear trend). The comparison with France shows that these cohort-effects of around 5 percent are not very strong.

In France, before including controls, the disposable income of the best-off 1950 birth cohort is 10.1 percent above the trend, while the worst-off 1920 and 1970-cohorts are 6.5 and 5 percent below the income trend. France is different from Germany as French cohorts are even more above or below the trend after including controls; including controls, the 1950-cohort is still 10.1 percent above the trend, but the first and last 1920 and 1975-cohort are 9 and 10.3 percent 
below it. This means that, even with the same education and other characteristics, people born in 1950 compared to 1975 have 20 percent higher disposable incomes than they should have, if all cohorts had profited similarly from increasing disposable incomes.

US cohort effects are minor compared to Germany and France. In the no-controls condition, the strongest effect is that the incomes of the 1950-cohort are 2.1 percent above the trend, while those of the 1960-cohort are 1.8 percent below it. In the controls condition, the income of the latest-born (1975) cohort is 6.2 percent above the trend, while the income of the worst-off 1955cohort is 3.9 percent below it. Therefore, before including controls, early- and late-born cohorts are disadvantaged in terms of disposable income in France and - to a lesser degree - in Germany; while in the US there is no clear trend before including controls. After including controls, German cohort effects largely vanish - only the 1945/1950-cohorts are slightly advantaged. In France however, after including controls, the incomes of mid-20th century cohorts are about 20 percentage points above the linear income trend, compared to the incomes of most disadvantaged 1920 and 1975-cohorts. The opposite is true for the US after including controls. Here, early- and late-born cohorts fare better than cohorts born in the middle of the $20^{\text {th }}$ century.

Including only education as a control variable, the graphs have very similar shapes as they have when all control variables are included (not shown here). Therefore, education is the main effect that weakens cohort effects in Germany, strengthens them in France and turns them on their head in the US. To understand the strength of cohort effects relative to the other significant control variables (thus not including sex), we compare them graphically for the three countries.

[Figure 2 here]

Figure 2 further illustrates how cohort membership scarcely influences income in the US and Germany, while French incomes are strongly influenced by cohort membership. For Germany, the strongest cohort effect of plus 5.8 percent, which goes together with being born in 1945, is much smaller than all significant control variables. ${ }^{13}$ In the US, the strongest cohort effect is 10 percent, which is the difference between the most advantaged 1975-cohort (6.2 percent above the disposable income trend) and the 1955-cohort (3.8 percent below). This is more than the effect of having one child (-5.8 percent), but it is weaker than all other significant control variables. In France, members of the most advantaged 1950-cohort are 20.4 percentage points above the trend for disposable incomes compared to the most disadvantaged 1975-cohort. This effect is comparable to having a secondary education compared to lower secondary (plus 21.2 percent); it is stronger than the effect of being an immigrant (-14.6 percent). However, the French effect of having a tertiary education (plus 58 percent) is almost three times as strong. Yet, in France, being part of the most disadvantaged, compared to the most advantaged cohort diminishes disposable income almost four times as much as having a child ( -5.2 percent), clearly more than having two children (-13.2 percent) and not quite as much as having three children (24.5 percent). Roughly speaking, the most advantaged and disadvantaged cohorts are about 5

${ }^{13}$ We checked our findings for Germany including the Eastern Länder and the results are similar (not shown here). 
percent apart in Germany, 10 percent in the US and 20 percent in France. This means that cohort effects are weaker than all controls in Germany and in the US (apart from having one child), while they are stronger than three out of seven control variables in France. ${ }^{14}$

The model that underlies these cohort effects absorbs linear cohort trends. Thus, it does not ascribe the effect of economic growth to successive cohorts, so that cohorts do not appear richer because of long-run linear economic growth. This makes sense when one is interested in how unequally cohorts participated in an overall trend of increasing incomes. However, it makes less sense to understand how the income of cohorts changed overall. The following section therefore includes the linear trend of increasing disposable income to understand how it interacts with the cohort effects just shown.

\section{TRENDED COHORT EFFECTS}

The APCT model ascribes linear trends that are not absorbed by age to a cohort effect. In the case of incomes, this makes sense in a descriptive way. It cannot tell us whether cohorts have a certain income due to a period or due to a cohort effect, but it shows which cohorts have what incomes due to any possible combination of the two. Thus, the ACPT shows how the disposable incomes of successive cohorts changed due to long-term economic growth and specific cohort effects, while it cannot disentangle which of the two accounts for the changes in income. We do not include the APCT regression table here, as it is exactly the same as the APCD table, with the only difference that the long term linear trend is now part of the cohort coefficients (the variable rescacoh is missing). ${ }^{15}$ However, the cohort effect remains controlled for age and non-linear effects. The following figures show the cohort effects after they include the linear disposable income trend.

[Figure 3 here]

The linear trend of increasing disposable incomes, which we have controlled in the APCD model, is now captured by the regression line. As the figures show, there have been substantial increases in inflation-adjusted disposable income in all countries. Focusing on the left-sided graphs, which represent the trend before controls, it is apparent that the disposable income of US cohorts correlates almost perfectly with general increases in disposable income, while correlations are weaker for France and Germany. ${ }^{16}$ How much different cohorts are above or below the trend is identical to the APCD model, so we do not elaborate on it here. The additional

\footnotetext{
${ }^{14}$ However, the control variables are relative to each opposed category, e.g. immigrants are compared to non-immigrants. Yet the cohort-variables are relative to the mean, e.g. the cohort-variables add up to zero. This makes the cohort effect look smaller.

${ }^{15}$ However, compare for the online annex that we uploaded, where we show the Stata code that we used for our calculations "ONLINE ANNEX - Code APC-T W Ger, FR, US, with and without controls."

16 We narrowed the US-sample to 20 percent its real size, to check if the small confidence intervals are due to the large US sample size, but we still got similar results. As in the APCD, our results remained the same when we looked at Germany including the New Länder (not shown here).
} 
benefit of the APCT model is that it shows that even in France, where cohort disposable incomes are furthest away from a linear increase, they are still strongly related to it $\left(\mathrm{r}^{2}=.94\right)$.

The graphs on the right show that, including controls, German and US cohort incomes remain close to general increases in disposable incomes. However, the disposable incomes of French cohorts now strongly diverge from general income trends. While the bumps around the linear trend are not different from the APCD model, the APCT shows that the cohort effect is so strong that after controls, inflation-adjusted incomes for French cohorts born after 1950 are flat. Thus, non-linear cohort effects in France are stronger than linear increases in economic growth (which can stem from a cohort or a period effect, this is impossible to disentangle). In the French control model, the $\mathrm{r}^{2}$ between general increases in incomes and cohort-based incomes is .99 until 1950 . Looking at the slope from 1920 to 1950, it becomes apparent that for the cohorts born until 1950, inflation-adjusted incomes increase by an average of 1.5 percent per year. For cohorts born after 1950, inflation-adjusted disposable incomes are flat. This means that if French cohorts had not improved their education and moved into dual-earner households (the two variables with the strongest income-increasing effect), then they would have experienced no gains in disposable income since 1950. The following sections analyze and discuss these results.

\section{ANALYSIS}

We find that, before including controls, French mid-20th century birth cohorts are more than 15 percent above the long-run trend of increasing disposable incomes, compared to late- and earlyborn $20^{\text {th }}$ century cohorts. We also find that West German mid-20 $0^{\text {th }}$ century cohorts are roughly 11 percent above the disposable income trend when compared to early and late-born cohorts, while the incomes of US mid-20 th century cohorts are only 2 percent above the trend of increasing incomes. However, German cohort effects largely result from changing educational levels. After controlling for education and other variables, the 1945/1950-cohorts are only about 5 percent above the income trend and no other cohorts deviate from the trend significantly. In France however, including controls strengthens cohort effects, so that the most advantaged mid-20 th century cohorts enjoy a roughly 20 percent advantage in disposable incomes over early- and late-born $20^{\text {th }}$ century cohorts. In the US, including controls turns the cohort-effect around. After controls, the latest, 1975-cohort has incomes almost 10 percent above the trend when compared to mid-20 th century cohorts.

We thus show that the mere chance of being born into a fortunate versus an unfortunate French birth cohort influences disposable incomes as much as a secondary education, while being born into the most unfortunate versus the most fortunate cohort decreases incomes as much as being an immigrant and almost as much as having three children. Controls show that increased education and moving into dual-earner households increased the incomes of later-born cohorts in Germany, so that they follow the trend of increasing incomes. In France, education has also expanded, but later cohorts still have significantly less disposable income than they would if they had profited from increasing disposable incomes as other cohorts did.

We then used a second model, which did not detrend disposable incomes for linear increases. This model showed that while the living standard of virtually each successive birth cohort in the US and Germany increased (even if some cohorts had higher increases than others), French cohort effects are so strong that after controls, successive post-1950-cohorts had no gains in inflation-adjusted disposable income, even though incomes increased overall. Since we looked at 
disposable income, including public payments and benefits, it is likely that our findings result from cohort-biased social policy. The last section discusses possible reasons why French post1950-cohorts have not participated in increases in disposable incomes as German- and UScohorts did.

\section{DISCUSSION}

The introduction showed a widespread speculation in the literature, that cohorts born around 1950 in Germany, the US and France are systematically advantaged, as they profited from an expanding education system, low unemployment and accommodating working markets. There is also a debate in these countries on whether mid-20th century birth cohorts monopolized lucrative positions and social transfers, thereby excluding younger generations. Our models (apart from the US-controls model) indeed show that the disposable incomes of cohorts born between 1940 and 1950 are well above what one would expect if all cohorts had equally participated in long-run increases in disposable incomes. For Germany, our results not only correct estimates of scholars who claim that cohorts born in the late 1940s and early 1950s are most advantaged (Mayer / Hillmert 2004; also cf. Lauterbach / Sacher 2001). More importantly, our data shows that much of this alleged cohort effect actually results from cohort-correlates in Germany. In this sense, we agree with studies which claim that belonging to a certain cohort in Germany is not as influential for one's living standard as e.g. class membership (cf. May 2012: 20).

For the US, our data contradicts studies that some cohorts are born to pay for others (Longman 1987; Kotlikoff 1992). In both the US and Germany, net of education and other controls, cohorts seem to share fairly equally in economic growth. Our results thus indicate that Germany and the US are fair in intergenerational terms. However, our data is alarming for France. After including controls, inflation-adjusted incomes of French cohorts born before 1950 increased on average by 1.5 percent annually, while cohorts born after 1950 have no increase in disposable incomes after adjusting for inflation. These results complement the bleak literature on French cohorts (Baudelot / Gollac 1997; Chauvel 1997a; Chauvel 1997b; Chauvel 2010a; Anguis / Cases / Surault 2002). They contradict the literature that sees a catch-up of later-born French cohorts (Bonnet 2010), though our data only reaches until 2004.

While our aim was to show, and not to explain this, our data fits the mechanisms, which the welfare state literature describes. The French welfare state is "dualized" in the sense that the traditional French social insurance system covered older cohorts fairly comprehensively, while newer cohorts have to cope with a retrenched system, covering fewer workers with fewer benefits (Palier 2010: 96f.). In addition, France lacks Germany's vocational training system to integrate young cohorts into a difficult working market.

Strong employment protection safeguards jobs and wages of older French cohorts, while making it hard for younger cohorts to enter the labor market, resulting in high youth unemployment (Chauvel 2010a). Overall, the insider-outsider dynamic that marks the Mediterranean welfare regime (Ferrera 1996; 2010) seems like a good candidate to explain the pronounced cohortdifferences that separate France from Germany and the US. So while some studies deny generational conflicts in Europe (Attias-Donfut / Arber 2000: 18), our study showed that generations in France have every reason to be in conflict, since the young and the very old are disadvantaged compared to mid-20 th century birth cohorts. 
In this sense, our results for France are alarming; they indicate that older generations have monopolized lucrative positions and social transfers, to the detriment of those born after 1950 . It does not seem unreasonable to assume that the "young" (in 2014, this comprises everyone below age 64) will not accept the stagnation of their disposable incomes indefinitely. To better understand the reasons for the cohort differences that we show, more research on the effect of the welfare state on cohorts is needed. We hope that our results inspire such research and raise awareness of how much the mere coincidence of being born into a certain birth cohorts has a large impact on whether one can participate in increases in living standards or not. 
Table 1: The age-period-cohort under-identification problem

\begin{tabular}{|c|ccccc|}
\hline$a \backslash p$ & 1985 & 1990 & 1995 & 2000 & 2005 \\
\hline 25 & 5 & 6 & 7 & 8 & 9 \\
30 & 10 & 11 & 12 & 13 & 14 \\
35 & 15 & 16 & 17 & 18 & 19 \\
40 & 20 & 21 & 22 & 23 & 24 \\
45 & 25 & 26 & 27 & 28 & 29 \\
50 & 30 & 31 & 32 & 33 & 34 \\
55 & 35 & 36 & 37 & 38 & 39 \\
\hline
\end{tabular}


Table 2: Cohort effects on disposable income in West Germany, France and the US

\begin{tabular}{|c|c|c|c|c|c|c|}
\hline & $\begin{array}{l}\text { West Germany } \\
\text { (1 no controls) }\end{array}$ & ( 2 controls) & $\begin{array}{l}\text { France } \\
\text { (3 no controls) }\end{array}$ & (4 controls) & $\begin{array}{l}\text { United States } \\
\text { (5 no controls) }\end{array}$ & (6 controls) \\
\hline \multirow[t]{2}{*}{ Cohort 1920} & $-0.0487^{* *}$ & -0.0339 & $-0.0648^{* * *}$ & $-0.0895^{* * *}$ & 0.0126 & $0.0372^{* * *}$ \\
\hline & $(-2.70)$ & $(-1.92)$ & $(-4.93)$ & $(-7.23)$ & $(1.24)$ & $(4.11)$ \\
\hline \multirow[t]{2}{*}{ Cohort 1925} & -0.0137 & 0.00103 & $-0.0305^{* *}$ & $-0.0494^{* * *}$ & 0.00734 & $0.0253^{* * *}$ \\
\hline & $(-0.94)$ & $(0.07)$ & $(-3.26)$ & $(-5.62)$ & $(0.92)$ & $(3.48)$ \\
\hline \multirow[t]{2}{*}{ Cohort 1930} & -0.0132 & -0.0190 & $-0.0317^{* * *}$ & $-0.0284^{* * *}$ & -0.0146 & -0.000440 \\
\hline & $(-1.08)$ & $(-1.66)$ & $(-3.67)$ & $(-3.48)$ & $(-1.92)$ & $(-0.06)$ \\
\hline \multirow[t]{2}{*}{ Cohort 1935} & -0.0120 & -0.00172 & -0.00583 & 0.00513 & $-0.0174^{* *}$ & -0.0103 \\
\hline & $(-1.09)$ & $(-0.16)$ & $(-0.73)$ & $(0.68)$ & $(-2.61)$ & $(-1.72)$ \\
\hline \multirow[t]{2}{*}{ Cohort 1940} & 0.0171 & 0.00340 & $0.0396^{* * *}$ & $0.0573^{* * *}$ & -0.00938 & $-0.0156^{*}$ \\
\hline & $(1.85)$ & $(0.39)$ & $(4.88)$ & $(7.54)$ & $(-1.38)$ & $(-2.49)$ \\
\hline \multirow[t]{2}{*}{ Cohort 1945} & $0.0744^{* * *}$ & $0.0584^{* * *}$ & $0.0847^{* * *}$ & $0.0930^{* * *}$ & $0.0156^{*}$ & $-0.0154^{* *}$ \\
\hline & $(7.08)$ & $(5.89)$ & $(10.32)$ & $(12.21)$ & $(2.52)$ & $(-2.79)$ \\
\hline \multirow[t]{2}{*}{ Cohort 1950} & $0.0600^{* * *}$ & $0.0462^{* * *}$ & $0.101^{* * *}$ & $0.101^{* * *}$ & $0.0206^{* * *}$ & $-0.0278^{* * *}$ \\
\hline & $(6.25)$ & $(5.14)$ & $(14.71)$ & (15.93) & $(3.61)$ & $(-5.40)$ \\
\hline Cohort 1955 & 0.0180 & 0.00238 & $0.0401^{* * *}$ & $0.0542^{* * *}$ & -0.00303 & $-0.0378^{* * *}$ \\
\hline & $(1.94)$ & $(0.28)$ & $(6.58)$ & $(9.67)$ & $(-0.63)$ & $(-8.85)$ \\
\hline Cohort 1960 & -0.00189 & -0.00597 & 0.00917 & $0.0339 * * *$ & $-0.0175^{* * *}$ & $-0.0316^{* * *}$ \\
\hline & $(-0.20)$ & $(-0.67)$ & $(1.59)$ & $(6.40)$ & $(-4.19)$ & $(-8.37)$ \\
\hline Cohort 1965 & -0.0102 & -0.0165 & $-0.0352^{* * *}$ & $-0.0164^{* *}$ & -0.00440 & -0.00413 \\
\hline & $(-1.00)$ & $(-1.70)$ & $(-5.55)$ & $(-2.85)$ & $(-1.05)$ & $(-1.09)$ \\
\hline Cohort 1970 & $-0.0241^{*}$ & -0.0169 & $-0.0563^{* * *}$ & $-0.0586^{* * *}$ & 0.00186 & $0.0184^{* * *}$ \\
\hline & $(-2.15)$ & $(-1.63)$ & $(-7.78)$ & $(-9.03)$ & $(0.36)$ & $(3.93)$ \\
\hline Cohort 1975 & $-0.0457^{* *}$ & -0.0176 & $-0.0499 * * *$ & $-0.103^{* * *}$ & 0.00841 & $0.0621^{* * *}$ \\
\hline & $(-2.85)$ & $(-1.17)$ & $(-5.66)$ & $(-12.85)$ & $(1.29)$ & $(10.64)$ \\
\hline Age 25 & $-0.0805^{* * *}$ & $-0.134^{* * *}$ & -0.0109 & $-0.0291^{* * *}$ & $-0.0980^{* * *}$ & $-0.134^{* * *}$ \\
\hline & $(-6.45)$ & $(-10.46)$ & $(-1.51)$ & $(-4.17)$ & $(-16.38)$ & $(-24.18)$ \\
\hline Age 30 & $-0.0521^{* * *}$ & $-0.0617^{* * *}$ & $-0.0237^{* * *}$ & $-0.0245^{* * *}$ & $-0.0858^{* * *}$ & $-0.0860^{* * *}$ \\
\hline & $(-5.86)$ & $(-7.16)$ & $(-4.32)$ & $(-4.87)$ & $(-19.89)$ & $(-22.12)$ \\
\hline Age 35 & $-0.0188^{*}$ & 0.00430 & $-0.0238^{* * *}$ & -0.00387 & $-0.0353^{* * *}$ & 0.00372 \\
\hline & $(-2.19)$ & $(0.52)$ & $(-4.42)$ & $(-0.77)$ & $(-8.20)$ & $(0.94)$ \\
\hline Age 40 & $0.0253^{* *}$ & $0.0648^{* * *}$ & 0.000151 & $0.0232^{* * *}$ & $0.0452^{* * *}$ & $0.0773^{* * *}$ \\
\hline & $(2.79)$ & $(7.57)$ & $(0.03)$ & $(4.15)$ & $(10.31)$ & $(19.51)$ \\
\hline Age 45 & $0.101^{* * *}$ & $0.140^{* * *}$ & $0.0471^{* * *}$ & $0.0530^{* * *}$ & $0.124^{* * *}$ & $0.134^{* * *}$ \\
\hline & $(11.50)$ & (17.19) & $(7.09)$ & $(8.52)$ & $(24.27)$ & (28.31) \\
\hline Age 50 & $0.124^{* * *}$ & $0.140^{* * *}$ & $0.0564^{* * *}$ & $0.0479^{* * *}$ & $0.161^{* * *}$ & $0.145^{* * *}$ \\
\hline & $(12.77)$ & $(14.91)$ & $(7.72)$ & $(7.07)$ & (28.78) & (28.85) \\
\hline Age 55 & $0.0758^{* * *}$ & $0.0665^{* * *}$ & 0.0148 & -0.00411 & $0.104^{* * *}$ & $0.0771^{* * *}$ \\
\hline & $(7.71)$ & $(7.19)$ & $(1.93)$ & $(-0.57)$ & $(16.91)$ & (13.81) \\
\hline Age 60 & $-0.0242 *$ & $-0.0455^{* * *}$ & $-0.0196^{* *}$ & $-0.0414^{* * *}$ & $0.0179^{* *}$ & -0.00533 \\
\hline & $(-2.44)$ & $(-4.87)$ & $(-2.68)$ & $(-5.99)$ & $(3.10)$ & $(-1.00)$ \\
\hline Age 65 & $-0.0610^{* * *}$ & $-0.0846^{* * *}$ & -0.0137 & $-0.0155^{*}$ & $-0.0664^{* * *}$ & $-0.0670^{* * *}$ \\
\hline & $(-6.09)$ & $(-8.99)$ & $(-1.95)$ & $(-2.35)$ & $(-12.07)$ & $(-13.39)$ \\
\hline Age 70 & $-0.0899 * * *$ & $-0.0893^{* * *}$ & $-0.0268^{* * *}$ & -0.00557 & $-0.166^{* * *}$ & $-0.145^{* * *}$ \\
\hline & $(-7.75)$ & $(-8.12)$ & $(-3.65)$ & $(-0.81)$ & $(-27.27)$ & $(-25.91)$ \\
\hline Period 1985 & $-0.0142^{* *}$ & $-0.0154^{* * *}$ & $-0.00687^{*}$ & 0.000918 & $0.0109^{* * *}$ & $0.0195^{* * *}$ \\
\hline & $(-3.19)$ & $(-3.64)$ & $(-2.04)$ & $(0.29)$ & $(3.76)$ & $(7.44)$ \\
\hline Period 1990 & $0.0297^{* * *}$ & $0.0311^{* * *}$ & $-0.0274^{* * *}$ & $-0.0289 * * *$ & -0.000158 & $-0.00857^{* *}$ \\
\hline & $(5.05)$ & $(5.52)$ & $(-6.08)$ & $(-6.75)$ & $(-0.05)$ & $(-2.92)$ \\
\hline Period 1995 & $-0.0223^{* *}$ & $-0.0203^{* *}$ & $0.0459^{* * *}$ & $0.0376^{* * *}$ & $-0.0436^{* * *}$ & $-0.0492^{* * *}$ \\
\hline & $(-3.06)$ & $(-2.94)$ & (11.32) & $(10.07)$ & $(-14.89)$ & $(-18.42)$ \\
\hline Period 2000 & $0.0121^{*}$ & 0.00885 & $0.0179^{* * *}$ & $0.00801 *$ & $0.0440 * * *$ & $0.0461^{* * *}$ \\
\hline & (2.39) & (1.93) & $(4.68)$ & (2.33) & $(16.61)$ & $(19.26)$ \\
\hline Period 2005 & -0.00540 & -0.00426 & $-0.0295^{* * *}$ & $-0.0176^{* * *}$ & $-0.0111^{* * *}$ & $-0.00782^{* * *}$ \\
\hline & $(-1.30)$ & $(-1.12)$ & $(-9.82)$ & $(-6.38)$ & $(-4.85)$ & $(-3.76)$ \\
\hline Cohort Trend & $0.443^{* * *}$ & $0.389^{* * *}$ & $0.533^{* * *}$ & $0.361^{* * *}$ & $0.542^{* * *}$ & $0.420^{* * *}$ \\
\hline & (22.09) & (20.39) & (34.82) & $(24.47)$ & (38.72) & (32.93) \\
\hline Age Trend & $0.183^{* * *}$ & $0.161^{* * *}$ & $0.231^{* * *}$ & $0.210^{* * *}$ & $0.235^{* * *}$ & $0.179 * * *$ \\
\hline & (16.88) & $(14.96)$ & (28.17) & $(25.46)$ & (32.03) & (25.92) \\
\hline Sec. Education & & $0.131^{* * *}$ & & $0.212^{* * *}$ & & $0.379^{* * *}$ \\
\hline & & (17.09) & & (45.41) & & (79.48) \\
\hline Tert. Education & & $0.393^{* * *}$ & & $0.581^{* * *}$ & & $0.751^{* * *}$ \\
\hline & & (41.23) & & (93.09) & & (149.85) \\
\hline Female & & 0.00761 & & 0.00377 & & $-0.0434^{* * *}$ \\
\hline & & $(1.28)$ & & $(0.91)$ & & $(-14.51)$ \\
\hline 1 Child & & $-0.0889 * * *$ & & $-0.0515^{* * *}$ & & $-0.0576^{* * *}$ \\
\hline & & $(-11.36)$ & & $(-8.43)$ & & $(-13.95)$ \\
\hline 2 Children & & $-0.183^{* * *}$ & & $-0.132^{* * *}$ & & $-0.175^{* * *}$ \\
\hline & & $(-21.96)$ & & $(-19.99)$ & & $(-40.77)$ \\
\hline$>2$ Children & & $-0.245^{* * *}$ & & $-0.220^{* * *}$ & & $-0.342^{* * *}$ \\
\hline & & $(-24.71)$ & & $(-30.66)$ & & $(-64.74)$ \\
\hline Partner in & & $0.298^{* * *}$ & & $0.259^{* * *}$ & & $0.352^{* * *}$ \\
\hline household & & (31.13) & & (42.42) & & (89.56) \\
\hline Immigrant & & $-0.202^{* * *}$ & & $-0.146^{* * *}$ & & $-0.175^{* * *}$ \\
\hline & & $(-23.97)$ & & $(-19.01)$ & & $(-47.44)$ \\
\hline Constant & $9.842^{* * *}$ & $9.544^{* * *}$ & $9.784^{* * *}$ & $9.484^{* * *}$ & $10.24^{* * *}$ & $9.699 * * *$ \\
\hline & $(2538.23)$ & (785.84) & (3726.85) & $(1368.60)$ & (4956.49) & (1674.37) \\
\hline $\mathrm{N}$ & 46225 & 44182 & 72886 & 70257 & 354527 & 338539 \\
\hline
\end{tabular}


Figure 1: Detrended cohort effects with and without controls
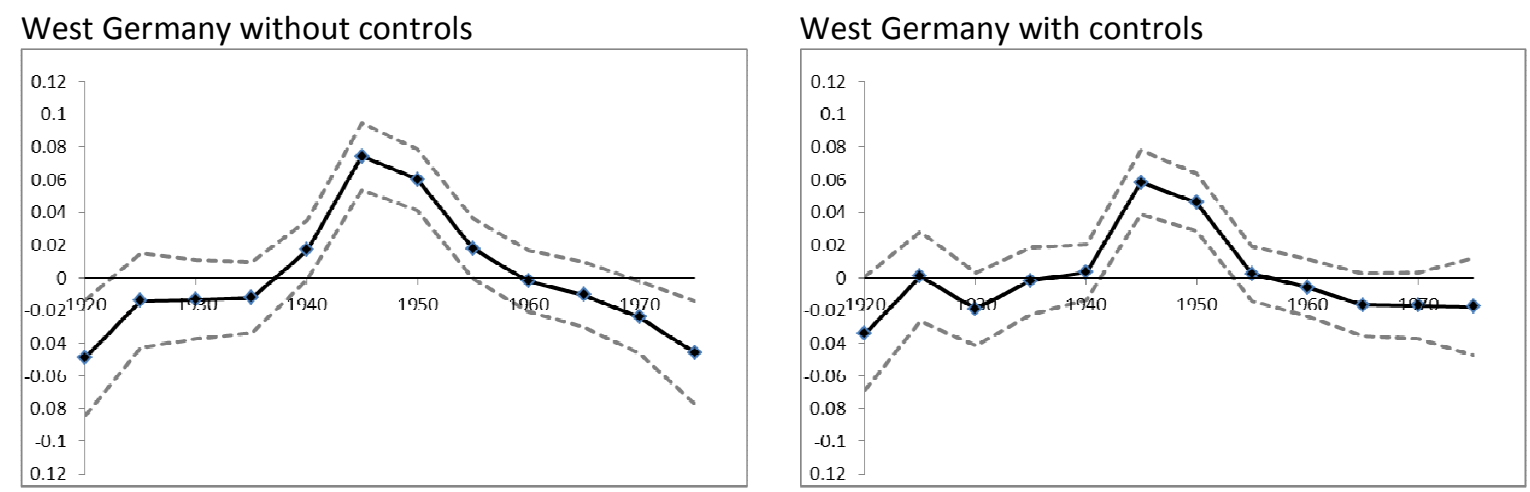

France without controls

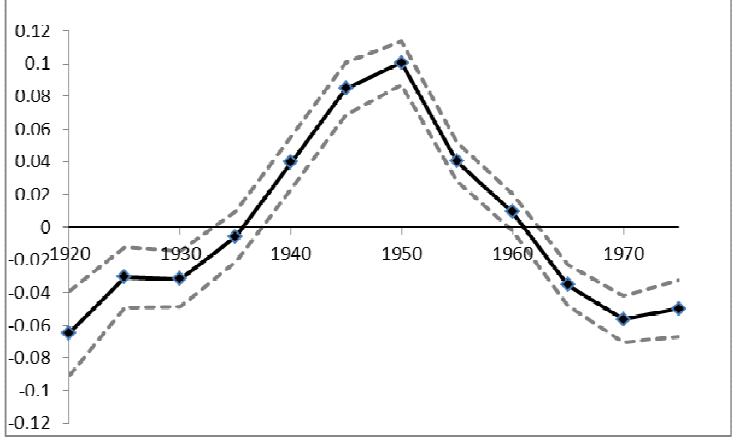

France with controls
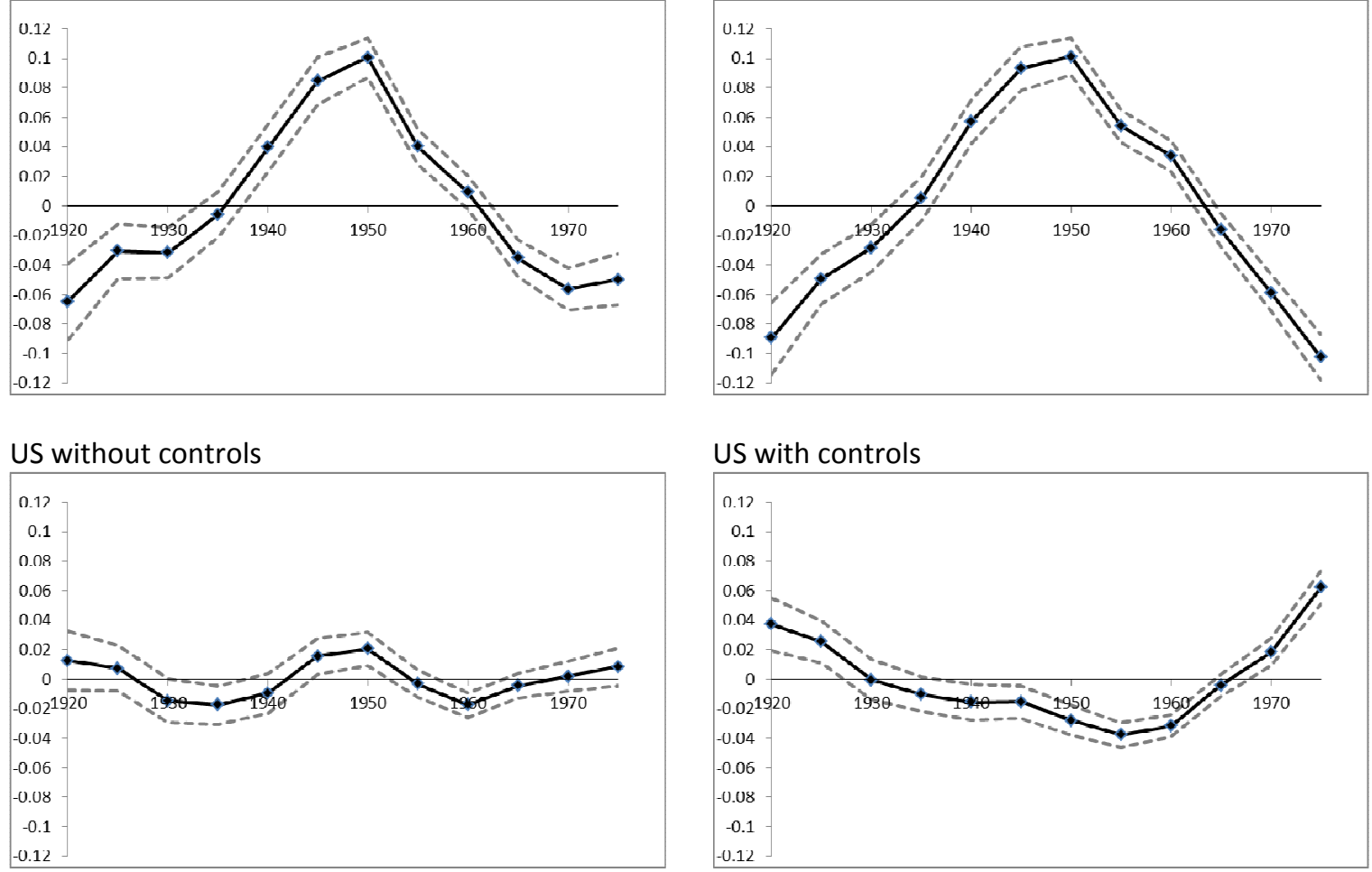
Figure 2: Effects on income from cohort-membership (born in years 1920-1975) and from control variables for W. Germany, France and the US
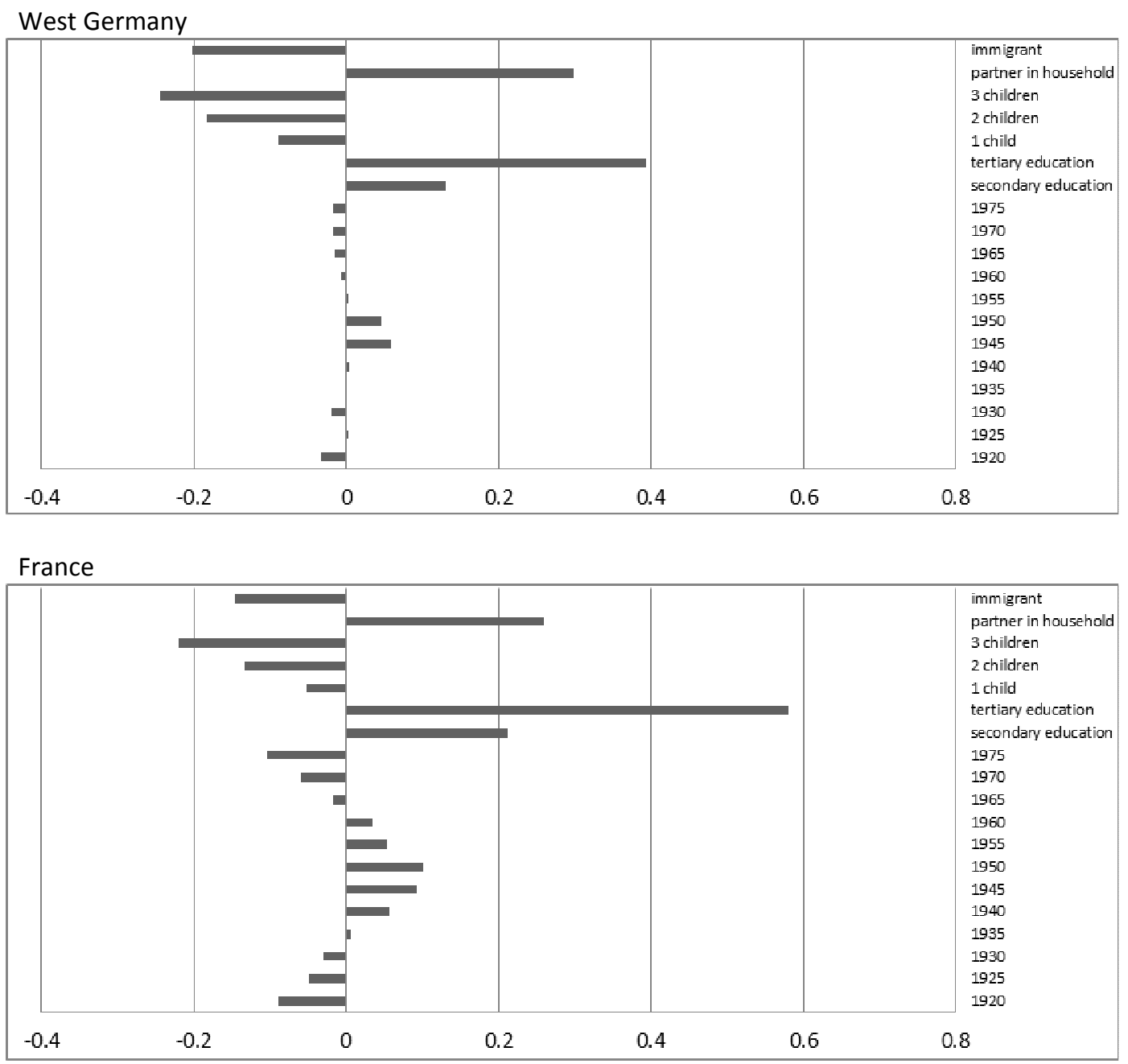

US

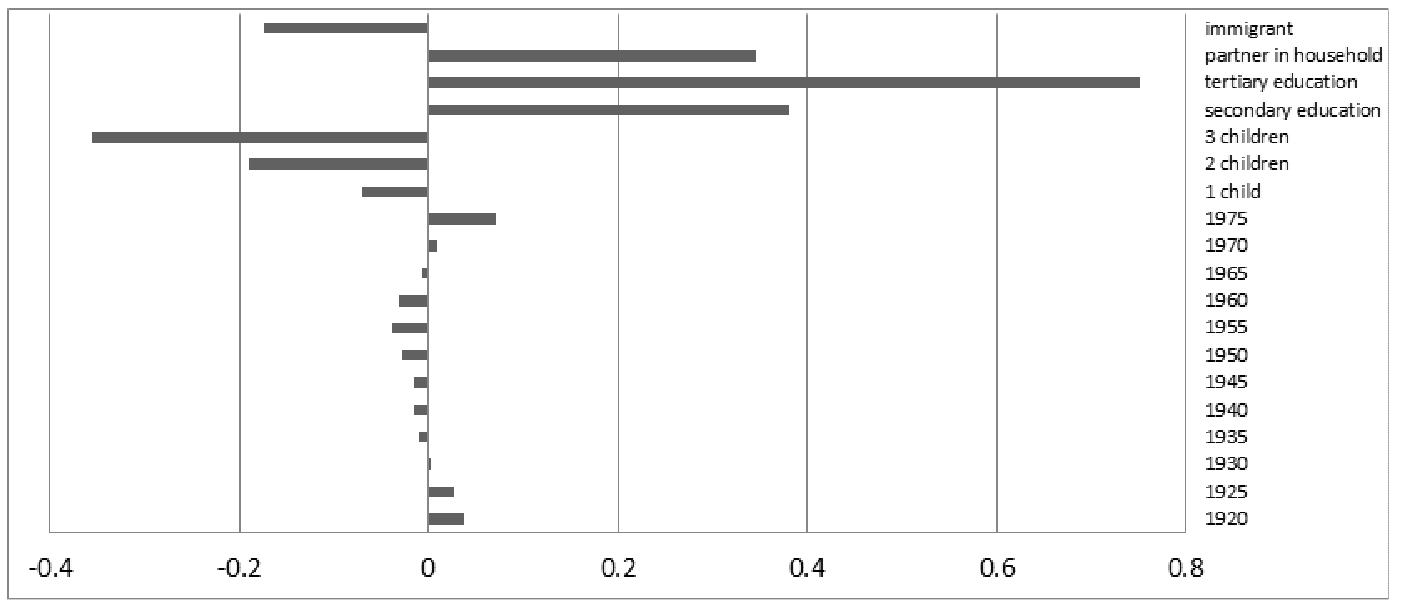


Figure 3: Trended cohort effects with and without controls
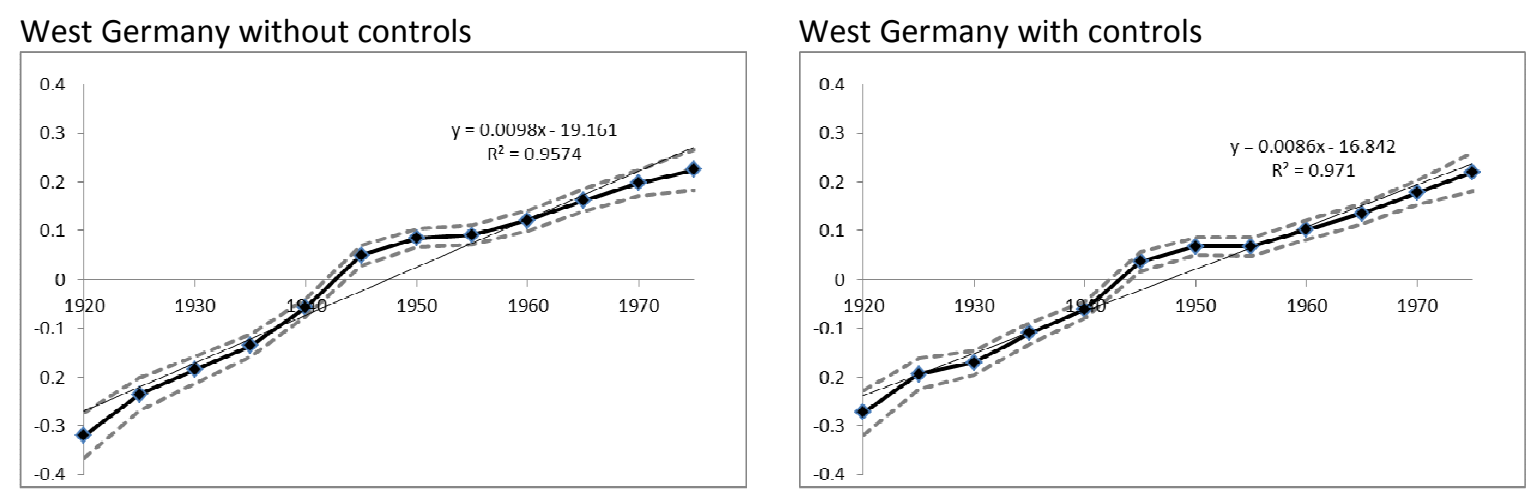

France without controls
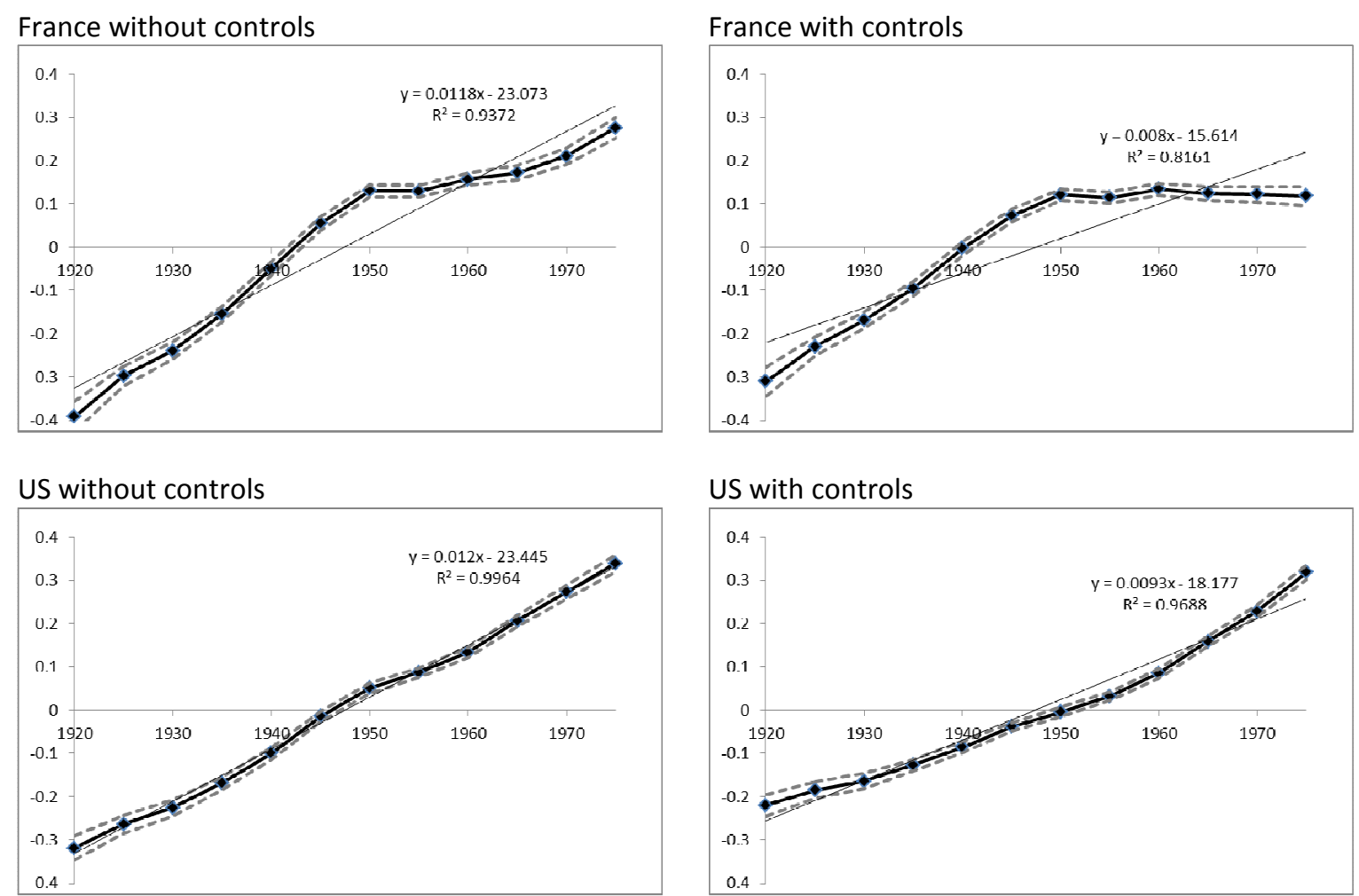


\section{References}

Anguis, Marie/Chantal Cases/Pierre Surault, 2002: L'évolution des suicides sur longue période : le rôle des effets d'âge, de date et de génération. In: Etudes et résultats 185, 1-7.

Antonczyk, Dirk/Thomas DeLeire/Bernd Fitzenberger, 2010: Polarization and Rising Wage Inequality: Comparing the U.S. and Germany. Centre for European Economic Research Discussion Paper No. 10-015. Bonn. <http://dx.doi.org/10.2139/ssrn.1589537>.

Attias-Donfut, Claudine/Sara Arber, 2000: Equity and Solidarity across the Generations. In: Sara Arber/Claudine Attias-Donfut (eds.), The Myth of Generational Conflict. The Family and State in Ageing Societies. London / New York: Routledge, 1-21.

Baudelot, Christian/Michel Gollac, 1997: Le salaire du trentenaire : question d'âge ou de génération ? In: Economie et statistique, 17-35.

<http://www.persee.fr/web/revues/home/prescript/article/estat 033614541997 num $30412554>$

Blossfeld, Hans-Peter, 1986: Career Opportunities in the Federal Republic of Germany: A Dynamic Approach to the Study of Life-Course, Cohort, and Period Effects. In: European Sociological Review 2, 208-225. <http://www.jstor.org/stable/522384>

Bommier, Antoine, et al., 2010: Who Wins and Who Loses? Public Transfer Accounts for US Generations Born 1850 to 2090. In: Population and Development Review 36, 1-26. $<\underline{\mathrm{http}: / / \mathrm{dx} . \mathrm{doi} .0 \mathrm{rg} / 10.1111 / \mathrm{j} .1728-4457.2010 .00315 . \mathrm{x}>}$

Bönke, Timm/Giacomo Corneo/Holger Lüthen, 2012: Lifetime earnings inequality in Germany. CEPR Discussion Paper no. 8929. London: Centre for Economic Policy Research. <http://www.cepr.org/pubs/dps/DP8929.asp>.

Bonnet, Carole, 2010: Niveaux de vie : un rattrapage des jeunes générations ? In: Regards croisés sur l'économie 7, 50-55.

Boockmann, Bernhard/Viktor Steiner, 2006: Cohort effects and the returns to education in West Germany. In: Applied Economics 38, 1135-1152. $<\underline{\text { http://dx.doi.org/10.1080/00036840500439168> }}$

Buchholz, Sandra, et al., 2009: Life Courses in the Globalization Process: The Development of Social Inequalities in Modern Societies. In: European Sociological Review 25, 53-71. $<$ http://esr.oxfordjournals.org/content/25/1/53.abstract $>$

Bugeja, Fanny, 2009: Housing crisis, generational inequalities and welfare states. In: Ian Rees Jones/Paul Higgs/David J. Ekerdt (eds.), Consumption and generational change: the rise and rise of consumer lifestyles and the transformation of later life. New Brunschwig (NJ): Transaction Publishers.

Chauvel, Louis, 1997a: Evolution du système de stratification sociale et succession des cohortes : grandeur et décadence des générations dans la société française des Trente glorieuses à nos jours. Lille: Lille I (USTL).

Chauvel, Louis, 1997b: L'uniformisation du taux de suicide masculin selon l'âge : effet de génération ou recomposition du cycle de vie? In: Revue française de sociologie XXXVIII, 681-734. 
Chauvel, Louis, 2010a: Le Destin des générations : structure sociale et cohortes en France du XXe siècle aux années 2010. Paris: PUF.

Chauvel, Louis, 2010b: Overeducation and social generations in France: Welfare regimes and intercohort inequalities in returns to education. In: Paul Attewell/Katherine S Newman (eds.), Growing Gaps: Educational Inequality Around the World. Oxford University Press: Oxford, 210-238.

Farges, Géraldine, 2012: Le statut social des enseignants français. In: Revue européenne des sciences sociales $49 .<\mathrm{http}: / /$ ress.revues.org/884>

Ferrera, Maurizio, 2010: The South European Countries. In: Francis G. Castles, et al. (eds.), The Oxford Handbook of the Welfare State. Oxford: Oxford University Press, 616-629.

Ferrera, Maurozio, 1996: The 'Southern Model' of Welfare in Social Europe. In: Journal of European Social Policy 6, 17-37.

Fienberg, Stephen E./William M. Mason, 1979: Identification and Estimation of Age-PeriodCohort Models in the Analysis of Discrete Archival Data. In: Sociological Methodology 10, $1-67$.

Fitzenberger, Bernd, et al., 2001: Testing for uniform wage trends in West-Germany: A cohort analysis using quantile regressions for censored data. In: Empirical Economics 26, 41-86. <http://dx.doi.org/10.1007/s001810000048>

Glenn, Norval D., 1976: Cohort Analysts' Futile Quest: Statistical Attempts to Separate Age, Period and Cohort Effects. In: American Sociological Review 41, 900-904.

<http://www.jstor.org/stable/2094738>

Goerres, Achim/Pieter Vanhuysse, 2012: Mapping the Field: The Comparative Study of Generational Politics and Policies. In: Achim Goerres/Pieter Vanhuysse (eds.), Ageing Populations in Post-industrial Democracies. Abingdon: Routledge/ECPR Studies in European Political Science, 1-22.

Holford, T R, 1991: Understanding the Effects of Age, Period, and Cohort on Incidence and Mortality Rates. In: Annual Review of Public Health 12, 425-457.

<http://www.annualreviews.org/doi/abs/10.1146/annurev.pu.12.050191.002233>

Holford, Theodore R., 1983: The Estimation of Age, Period and Cohort Effects for Vital Rates. In: Biometrics 39, 311-324. <http://www.jstor.org/stable/2531004>

Holford, Theodore R., 1985: An Alternative Approach to Statistical Age-Period-Cohort Analysis. In: Journal of Chronic Diseases 38, 831-836.

<http://www.sciencedirect.com/science/article/pii/0021968185901067>

Kant, Immanuel, 1784: Idee zu einer allgemeinen Geschichte in weltbürgerlicher Absicht. In: Berlinische Monatsschrift, 385-411. <http://gutenberg.spiegel.de/buch/3506/1>

Karamessini, Maria, 2008: Continuity and Change in The Southern European Social Model. In: International Labour Review 147, 43-70. <http://dx.doi.org/10.1111/j.1564913X.2008.00023.X>

Kohli, Martin, 2006: Alt-Jung. In: Stephan Lessenich/Frank Nullmeier (eds.), Deutschland - eine gespaltene Gesellschaft. Frankfurt / New York: Campus, 115-135. 
Kopczuk, Wojciech/Emmanuel Saez/Jae Song, 2010: Earnings Inequality and Mobility in the United States: Evidence from Social Security Data Since 1937. In: The Quarterly Journal of Economics 125, 91-128. <http://qje.oxfordjournals.org/content/125/1/91.abstract>

Kotlikoff, Laurence J., 1992: Generational accounting: knowing who pays, and when, for what we spend. New York: Free Press.

Koubi, Malik, 2003: Les trajectoires professionnelles : une analyse par cohorte. In: Economie et statistique, 119-147.

<http://www.persee.fr/web/revues/home/prescript/article/estat 033614542003 num 3691 7288>

Lauterbach, Wolfgang/Matthias Sacher, 2001: Erwerbseinstieg und erste Erwerbsjahre. In: KZfSS Kölner Zeitschrift für Soziologie und Sozialpsychologie 53, 258-282. <http://dx.doi.org/10.1007/s11577-001-0039-9>

Lessenich, Stephan, 1994: Three Worlds of Welfare Capitalism - oder vier? Strukturwandel arbeits- und sozialpolitischer Regulierungsmuster in Spanien. In: Politische Vierteljahresschrift 35, 224-244.

Liebig, Stefan/Percy Scheller, 2007: Gerechtigkeit zwischen den Generationen. In: Berliner Journal für Soziologie 17, 301-321. <http://dx.doi.org/10.1007/s11609-007-0027-7>

Longman, Phillip, 1987: Born to pay : the new politics of aging in America. Boston: Houghton Mifflin.

Luo, Liying, 2013: Assessing Validity and Application Scope of the Intrinsic Estimator Approach to the Age-Period-Cohort Problem. In: Demography 50, 1945-1967. <http://dx.doi.org/10.1007/s13524-013-0243-z>

Malmendier, Ulrike/Stefan Nagel, 2011: Depression Babies: Do Macroeconomic Experiences Affect Risk Taking? In: The Quarterly Journal of Economics 126, 373-416. $<$ http://qje.oxfordjournals.org/content/126/1/373.abstract $>$

Mannheim, Karl, 1928: Das Problem der Generationen. In: Kölner Vierteljahreshefte für Soziologie 7, 157-185, 309-330.

Mason, Karen Oppenheim, et al., 1973: Some Methodological Issues in Cohort Analysis of Archival Data. In: American Sociological Review 38, 242-258.

<http://www.jstor.org/stable/2094398>

Mason, William M./Nicholas H. Wolfinger, 2001: Cohort Analysis. In: J. Smelser Neil/B. Baltes Paul (eds.), International Encyclopedia of the Social \& Behavioral Sciences. Oxford: Pergamon, 2189-2194.

<http://www.sciencedirect.com/science/article/pii/B0080430767004010>

May, Christina, 2012: Generation in Itself or for Itself? In: European Societies 15, 4-25. <http://dx.doi.org/10.1080/14616696.2012.748927>

Mayer, Karl Ulrich, 2005: Life Courses and Life Chances in a Comparative Perspective. In: Stefan Svallfors (ed.) Analyzing Inequality: Life Chances and Social Mobility in Comparative Perspective. Stanford, CA: Stanford University Press, 17-55.

Mayer, Karl Ulrich, 2009: New Directions in Life Course Research. In: Annual Review of Sociology 35, 413-433. <http://www.annualreviews.org/doi/abs/10.1146/annurev.soc.34.040507.134619> 
Mayer, Karl Ulrich/Steffen Hillmert, 2004: New Ways of Life or Old Rigidities? Changes in Social Structures and Life Courses and their Political Impact. In: Wolfgang Streeck/Herbert Kitschelt (eds.), Germany: Beyond the Stable State. London/Portland, OR: Frank Cass, 79100.

Myles, John, 2002: A New Social Contract for the Elderly? In: Gøsta Esping-Andersen (ed.) Why we need a new welfare state. Oxford Oxford University Press, 130-172.

O’Brien, Robert M., 2011: Constrained Estimators and Age-Period-Cohort Models. In: Sociological Methods \& Research 40, 419-452.

<http://smr.sagepub.com/content/40/3/419.abstract>

Osberg, Lars, 2003: Long Run Trends in Income Inequality in the United States, UK, Sweden, Germany and Canada: A Birth Cohort View. In: Eastern Economic Journal 29, 121. $<$ http://search.ebscohost.com/login.aspx?direct=true \&db=buh\&AN=9187832\&site=eho st-live $>$

Palier, Bruno, 2010: The Dualizations of the French Welfare System. In: Bruno Palier (ed.) A Long Goodbye to Bismarck? The Politics of Welfare Reforms in Continental Europe. Amsterdam: Amsterdam University Press, 73-99.

Pampel, Fred C./Lori M. Hunter, 2012: Cohort Change, Diffusion, and Support for Environmental Spending in the United States. In: American Journal of Sociology 118, 420-448. <http://www.jstor.org/stable/10.1086/666506>

Raftery, Adrian, 1986: Choosing Models of Cross-Classification. In: American Sociological Review $51,145-146$.

Rodgers, Willard L., 1982: Estimable Functions of Age, Period, and Cohort Effects. In: American Sociological Review 47, 774-787. <http://www.jstor.org/stable/2095213>

Schröder, Martin, 2013: Integrating Varieties of Capitalism and Welfare State Research: A Unified Typology of Capitalisms. New York: Palgrave.

Thelen, Kathleen, 2012: Varieties of Capitalism: Trajectories of Liberalization and the New Politics of Social Solidarity. In: Annual Review of Political Science 15, 137-159.

Tu, Yu-Kang, et al., 2011: Unravelling the Effects of Age, Period and Cohort on Metabolic Syndrome Components in a Taiwanese Population Using Partial Least Squares Regression. In: BMC Medical Research Methodology 11, 82.

<http://www.biomedcentral.com/1471-2288/11/82>

Yang, Yang/Kenneth Land, 2013: Age-Period-Cohort Analysis: New Models, Methods, and Empirical Applications. New York: Chapman and Hall/CRC.

Yang, Yang/Kenneth C. Land, 2008: Age-Period-Cohort Analysis of Repeated Cross-Section Surveys: Fixed or Random Effects? In: Sociological Methods \& Research 36, 297-326. <http://smr.sagepub.com/content/36/3/297.abstract>

Yang, Yang, et al., 2008: The Intrinsic Estimator for Age-Period-Cohort Analysis: What It Is and How to Use It. In: American Journal of Sociology 113, 1697-1736. 